\title{
STRESS RUPTURE CONSIDERATIONS IN THE DESIGN OF LARGE APERTURE, LOW MASS COMPOSITE VACUUM WINDOWS*
}

\author{
W.J. Leonhardt, J.R. Cullen and P.F. Gill \\ Brookhaven National Laboratory, Upton, NY 11973
}

\begin{abstract}
Large vacuum vessels are often employed in High Energy and Nuclear Physics experiments to provide a volume for particle traverse in the absence of air molecules. The ends of these vessels generally have a large aperture which is closed with a thin membrane known as a vacuum window. To minimize the vacuum window mass, composites of Kevlar and Mylar have been used in window construction. Historically, these windows have been designed based on the ultimate tensile strength of the materials, however, following the costly failure of a $193 \mathrm{~cm} \mathrm{x} 86 \mathrm{~cm}$ window, other design methods emerged. This paper reviews the history of window design and describes the window failure and possible causes. It further presents the phenomenon of stress rupture and describes the analytical and experimental work carried out to improve composite window design methods.
\end{abstract}

\section{INTRODUCTION}

Several experiments utilizing protons and heavy ions in the BNL-AGS employ large vacuum vessels as part of the beamline apparatus. Generally, these vacuum vessels have a portion or portions of their wall made thin so as to have the minimum impact on particles passing through them. These thin areas are known as vacuum windows.

Vacuum windows are fabricated from materials where the density is minimized yet sufficient strength is provided so the windows operate safely and reliably for long periods of time. Several materials have been considered $[1,2]$, however BNL utilizes dry combinations of Kevlar ${ }^{\mathrm{TM}}$ and Mylar ${ }^{\mathrm{TM}}$ exclusively.

\section{ANALYTICAL APPROACH}

\subsection{Timoshenko Relations}

Design of rectangular Kevlar/Mylar composite windows has traditionally been based upon classical Timoshenko [3] formulas for thin plates where membrane stresses dominate. The stress formula is:

*This research was supported by the U.S. Department of Energy under Contract Nos. DE-AC02-76CH00016.

$$
\sigma=K_{1}\left(E\left(\frac{p a}{t}\right)^{2}\right)^{1 / 3}
$$

Transverse and angular deflections are calculated using respectively:

$$
\delta=K_{2}\left(\frac{p a^{4}}{E t}\right)^{1 / 3} \text { and, } \theta=\mathrm{K}_{3}\left(\frac{p a}{E t}\right)^{1 / 3}
$$

Modulus of elasticity (E), pressure (p), length of the short side (a), and thickness ( $\mathrm{t}$ ) of the membrane take on any consistent set of units. $\mathrm{K}_{1} \mathrm{~K}_{2}$ and $\mathrm{K}_{3}$ are coefficients which depend upon the ratio of the length of the long side to short side of the window and range in value from 0.273 to 0.346 for $K_{1}, 0.320$ to 0.360 for $K_{2}$, and 1.280 to 1.440 for $\mathrm{K}_{3}$. For rectangular windows the Kevlar fabric is oriented such that the weave is parallel to the window edge. Membrane thickness is taken as the equivalent solid thickness of the fibers running perpendicular to the window edge.

Experience has shown that these formulae do not accurately predict the pressures at which window assemblies fail. This is probably due to the large deflections of these windows. Consequently, designers have come to rely upon an iterative process of testing to failure then applying a suitable factor of safety in a subsequent design.

\subsection{ANSYS}

More recently the ANSYS finite element program has been applied to the analysis of these problems to both improve the accuracy beyond Timoshenko's relations and give a better idea of the stress distributions in a given geometry.

Generally a 2-D plane model is sufficient. To create the model a geometric quarter section is generated taking advantage of symmetry. SHELL41 elements with membrane option are used. A second layer of elements is placed over the first to model the Mylar layer. In this way stresses can be obtained for both the Kevlar and Mylar. This is useful since in some window designs the thickness of the Mylar not the Kevlar is the limiting factor in the 
design. A solution is obtained using stress stiffening and large deflection options available in the program. Results of these analyses more closely predict failure stresses as is shown in the following section.

\subsection{Experimental Data}

Several windows with various geometries have been analyzed and tested to destruction. They are listed in Table I. Window rectangular dimensions are $1930 \mathrm{~mm} \mathrm{x}$ $860 \mathrm{~mm}$ except as noted.

TABLE I

WindOW FAILURE PRESSURE AND CALCULATED STRESS

\begin{tabular}{ccccc}
\hline $\begin{array}{c}\text { Dimensions } \\
\text { Kevlar/Mylar } \\
(\mathrm{mm})\end{array}$ & $\begin{array}{c}\text { Pressure @ } \\
\text { Failure } \\
(\mathrm{MPa})\end{array}$ & $\begin{array}{c}\text { Calculated Stress } \\
\text { Timoshenko } \\
(\mathrm{MPa})\end{array}$ & $\begin{array}{c}\text { ANSYS } \\
(\mathrm{Mpa})\end{array}$ & $\begin{array}{c}\text { Kevlar } \\
\text { Strength } \\
(\mathrm{MPa})\end{array}$ \\
\hline $0.43 / 0.13$ & 0.276 & 2350 & 2575 & 2925 \\
$0.43 / 0.05$ & 0.248 & 2190 & 2470 & 2925 \\
$0.41 / 0.13$ & 0.308 & 2970 & 3110 & 3380 \\
$0.38 / 0.13$ & 0.262 & 2570 & 2810 & 2925 \\
$0.38 / 0.13^{\mathrm{a}}$ & 0.324 & 2340 & 2570 & 2925 \\
$0.30 / 0.13^{\mathrm{a}}$ & 0.248 & 2175 & 2330 & 2925 \\
$0.30 / 0.05^{\mathrm{a}}$ & 0.227 & 2050 & 2280 & 2925 \\
$0.25 / 0.05^{\mathrm{b}}$ & 0.379 & 2600 & 2565 & 3000 \\
\hline a $1220 \mathrm{~mm} \times 610 \mathrm{~mm}$ & b $457 \mathrm{~mm}$ dia. & &
\end{tabular}

For rectangular shapes, the Timoshenko expression results in stresses which are about $10 \%$ below ANSYS results which are in turn 10\%-20\% below the actual Kevlar fiber strength. Although ANSYS results appear to more accurately represent failure stresses, the reason for apparent differences is not well understood, therefore, at the present time, testing to failure with application of a suitable safety factor for the specific window is still necessary.

\section{WINDOW DESIGN}

Specific details of window design are given elsewhere $[1,2]$ and are briefly repeated here for convenience. Components of a typical window assembly are shown in Figure 1. In this figure, the Mylar vacuum membrane and the Kevlar are fabricated to fully cover the aperture and the area under the clamp flange, while the Mylar ring has the aperture cut out and exists under the clamp flange. The Kevlar and Mylar are assembled dry, that is without any epoxy impregnating the Kevlar except for an epoxy bead opposite the o-ring seal to prevent edge leakage while under vacuum. The aluminum wire serves as an aide in clamping.

\section{BNL WINDOW HISTORY}

BNL has utilized circular composite windows of 343 , 457, 914 and $965 \mathrm{~mm}$ diameter and rectangular windows measuring $1220 \mathrm{~mm}$ by $610 \mathrm{~mm}, 1930 \mathrm{~mm}$ by $860 \mathrm{~mm}$,
$2119 \mathrm{~mm}$ by $429 \mathrm{~mm}$ and $2776 \mathrm{~mm}$ by $500 \mathrm{~mm}$. The thickness of the Kevlar and Mylar material used in these designs was determined by considering the material's ultimate tensile strength and then specifying a thickness to provide an adequate margin of safety. Experimental testing of windows to failure was accomplished to confirm the analytical strength predictions.



Figure 1 Typical Window Assembly

In the spring of 1995 , the 1930 by 860 window failed while operating under full vacuum. Fortunately, this implosion caused no personnel injury however approximately a quarter of a million dollars of experimental equipment was lost. A post failure investigation identified two possible causes for the failure. The first was the presence of a metal chip trapped in the window material near the clamp flange. This chip may have caused a stress concentration in one or both materials, resulting in the failure. The second possible cause was that the Kevlar material failed due to a phenomenon known as stress rupture. Stress rupture lifetimes are not accurately predictable, however the failed window was analyzed and it was judged that stress rupture could have been a contributing cause.

\section{STRESS RUPTURE PHENOMENON}

"Stress rupture is the sudden failure (break) in a material held for long periods of time under loads which are less (sometimes considerably less) than the nominal tensile strength of the material. The greater the load, the more quickly failure occurs. Inversely, even the smallest load could theoretically cause stress rupture if enough time were allowed. The stress rupture properties of wet and dry yarns are the same."[4] Values of the stress rupture properties of Kevlar yarns are shown in Figure 2.

\section{STRESS RUPTURE TESTING}

Although stress rupture data was available for Kevlar yarns, it was decided to perform independent 
measurements on the stress rupture performance of the

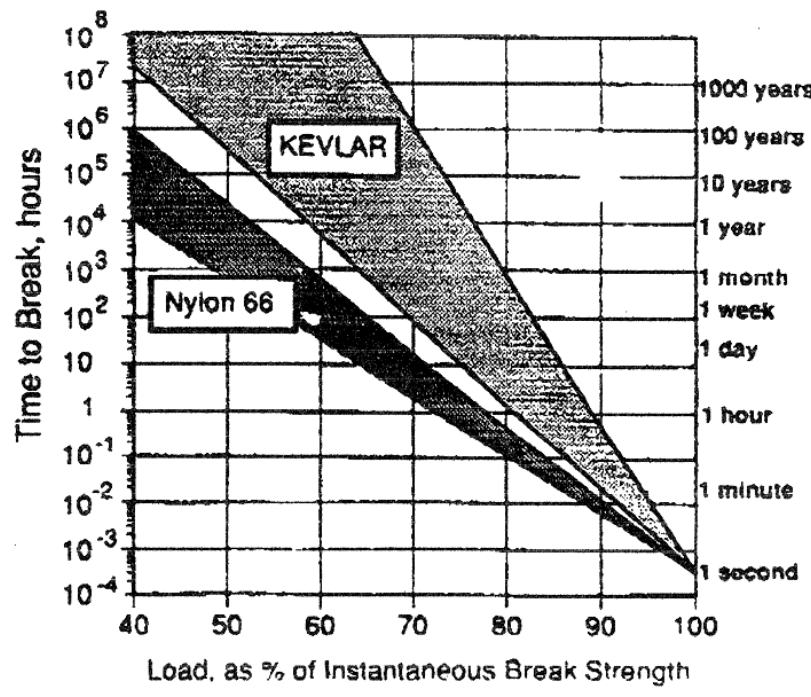

Figure 2 Stress Rupture of Kevlar Yarns [4]

Kevlar cloth. Samples of Kevlar 129 fabric were loaded in tension using a standard Instron tensile testing machine with custom made gripping fixtures to hold the cloth. This setup is essentially the same as is used to measure the tensile strength of cloth samples except, in stress rupture testing, the force on the sample is kept constant.

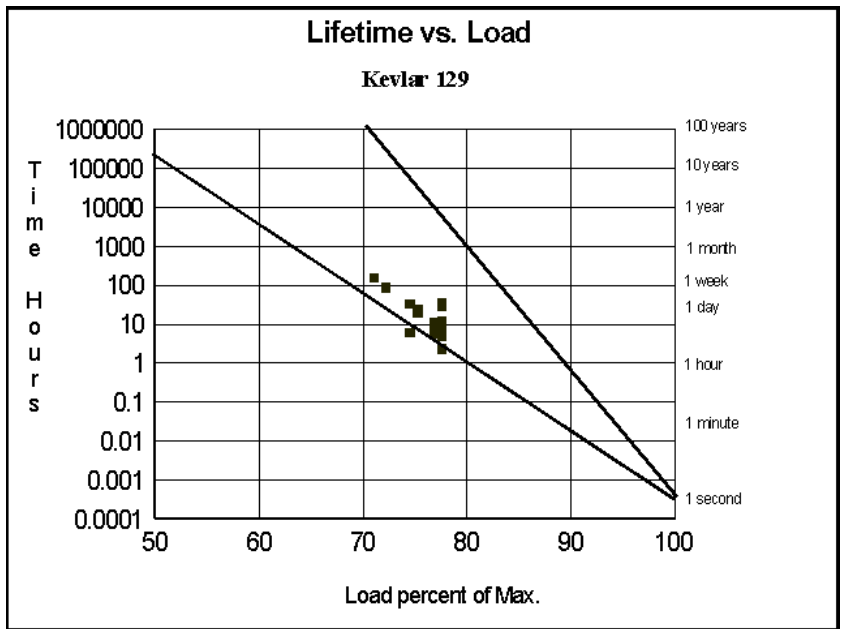

Figure 3 Stress Rupture Experimental Data

Alignment and uniform loading systematics were minimized empirically by loading the samples to failure and comparing differences in the ultimate tensile strength. It was discovered that removing edge fibers increased the ultimate tensile strength since there could be damage during cutting and distortion in the fabric near the free edge. The final width of all samples tested was $37 \mathrm{~mm}$. This technique also has the advantage of enhanced sample reproducibility by maintaining a constant number of fibers between samples.

The results of the stress rupture measurements are shown in Figure 3. The measuring period for the data taken is between one hour and one week. The data show good agreement with the DuPont values shown in Figure 2 and the lines plotted in Figure 3 are the upper and lower bounds from Figure 2. The data also show good agreement with a study performed by Chiao,, et. al. [5] of Kevlar49/epoxy pressure vessels which found that vessels loaded to $50 \%$ of their burst pressure had no failures in 9 years.

\section{SUMMARY}

Composite vacuum windows are an extremely useful piece of experimental apparatus that need to be designed carefully. In the design process, it is imperative to consider both the Kevlar ultimate tensile strength and its stress rupture lifetime. Experiments have shown that the catalog values for stress are reasonable and it is recommended that the most conservative values be used. Since experimental sensitivity is also important, current BNL policy is to provide windows with a minimum of a 100 year lifetime (which corresponds to a stress level of approximately $47 \%$ of the strength) and to replace the window after one year under load. A ten year lifetime is allowable with special review.

\section{ACKNOWLEDGMENTS}

The authors wish to acknowledge valuable input on stress rupture and finite element modeling from J. Kilmer and A. Lee of Fermi National Accelerator Laboratory.

Kevlar and Mylar are registered trademarks of E.I du Pont de Nemours and Co., Inc.

\section{REFERENCES}

[1] W.J. Leonhardt and M. Mapes, "Design of Large Aperature, Low Mass Vaccuum Windows," Proc. of 1993 Particle Accelerator Conf. pp 3882-3884

[2] M. Mapes and W.J. Leonhardt, "Design of Large Aperature, Low Mass Vacuum Windows," J. Vac. Sci Technol. A, 11(4), Jul/Aug 1993, pp 1587-1592.

[3] S. Timoshenko and S. Woinowsky-Krieger, Theory of Plates and Shells, McGraw Hill, N.Y., 2/e, 1959.

[4] Data Manual for Fiber Optic and Other Cables, E.I du Pont de Nemours and Co., Inc., July 1991

[5] T.T. Chiao and R.L. Moore, "Fiber/Epoxy Filament-Wound Vessels Final Report," Report UCID-20845 Lawrence Livermore Labratory, August 1986 